\title{
Węzeł hybrydowy - prognozowanie skurczu poprzecznego złącza doczołowego na podstawie planowanego eksperymentu dwuwartościowego
}

\section{Hybrid node - predictions of transverse shrinkage in butt join on the basis of twodimensional designed experiment}

\section{Streszczenie}

W artykule przedstawiono wyniki badań eksperymentalnych skurczu poprzecznego złącza doczołowego węzła hybrydowego. Badania przeprowadzono wg zasad techniki planowania eksperymentu w warunkach laboratoryjnych, zbliżonych do warunków panujących w przemyśle. Przedstawiona analiza uwzględnia parametry technologiczno-konstrukcyjne wpływające na przydatność montażową wielkogabarytowej konstrukcji stalowej. Pokazana metoda oceny wyników eksperymentalnych umożliwia wykorzystanie zależności aproksymacyjnej do prognozowania skurczu poprzecznego w konstrukcjach wielkogabarytowych.

Słowa kluczowe: węzeł hybrydowy, odkształcenia spawalnicze, skurcz poprzeczny, planowanie eksperymentu, modele predykcyjne

\section{Abstract}

The article presents the results of experimental research on transverse shrinkage in butt joint of a hybrid node. The research has been carried out according to design of experiment technique in laboratory conditions near-real-life production conditions. The presented analysis accounts for technological-constructional parameters influencing the suitability for assembly of largesize steel construction. The presented appraisal method used for experiment results features implementation of approximation dependence to predict transverse shrinkage in large-size constructions.

Keywords: hybrid node, weld distortions, transverse shrinkage, design of experiment, prediction models

\section{Wstęp}

Artykuł stanowi kontynuację tematu poświęconego prognozowaniu odkształceń spawalniczych węzła hybrydowego. Pierwszy artykuł, analizujący odkształcenia panelu Icore, ukazał się w Przeglądzie Spawalnictwa w marcu 2012 roku [1].

Celem jednoznacznego sprecyzowania poruszanych w tekście zagadnień zaadaptowano następujące określenia, $[2,3]$ :

- węzeł hybrydowy - szczególny fragment wielkogabarytowej konstrukcji stalowej (np. okrętowej), w którym łączą się dwie odmienne pod względem konstrukcyjno-technologicznym części tej konstrukcji (w analizowanym przypadku - patrz rys. 1: panel sandwich typu l-core oraz płyta usztywniona konwencjonalnie). Oba fragmenty konstrukcji zespolone są elementem pośrednim - łącznikiem,

- przydatność montażowa - zdolność konstrukcji, bądź jej fragmentu, do połączenia z inną konstrukcją, bądź jej fragmentem, najlepiej bez dodatkowych zabiegów korekcyjnych. Najbardziej niepożądanymi zjawiskami, wpływającymi na jakość elementów spawanych są odkształcenia spawalnicze.
To one, w znaczący sposób, pogarszają przydatność montażową prefabrykowanych podzespołów technologicznych we wszystkich rodzajach wielkogabarytowych konstrukcji stalowych. Znaczną cześć nakładów (zarówno praco, materiałochłonności) pochłaniają prace naprawcze - głównie prostowanie termiczne - poprawiające złą jakość sekcji (tzn. nieakceptowaną z punktu widzenia standardów wykonania konstrukcji wielkogabarytowych, np.: [4,5]. Jakość wykonania sekcji na etapie prefabrykacji decyduje w znacznym stopniu o ich przydatności montażowej w późniejszych etapach budowy jednostki pływającej [6].

Pierwszą operacją technologiczną wchodzącą w skład prefabrykacji wszystkich rodzajów sekcji kadłuba statku jest spawanie płatów poszycia. Operacja ta występuje również w późniejszych etapach montażu, tj. podczas budowy wielkogabarytowych sekcji przestrzennych (bloków) oraz montażu kadłuba w całość. Dlatego złącze doczołowe jest jednym z podstawowych i najistotniejszych elementów konstrukcji spawanych, posiadającym decydujący wpływ na przydatność montażową każdej sekcji. Ponadto złącza

Dr inż. Tomasz Urbański - Zachodniopomorski Uniwersytet Technologiczny w Szczecinie.

Autor korespondencyjny/Corresponding author. tomasz.urbanski@zut.edu.pl 
doczołowe mają duże znaczenie dla wytrzymałości wzdłużnej kadłuba statku.

Również w przypadku węzła hybrydowego ta postać odkształcenia ma bardzo ważne znaczenie. Skurcz poprzeczny zajmuje bowiem trzecią pozycję w tzw. hierarchii technologicznej postaci odkształceń spawalniczych węzła. W/w hierarchię stworzono celem uszeregowania analizowanych form deformacji pod kątem ich wpływu na przydatność montażową. Szczegółową analizę, dotyczącą wpływu wszystkich postaci odkształceń spawalniczych węzła hybrydowego na jego technologiczną przydatność montażową zawarto w [3].

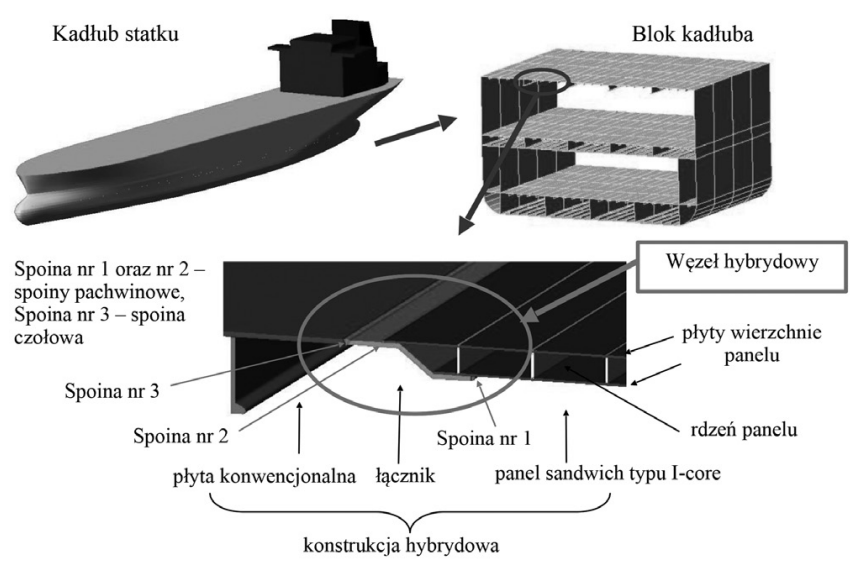

Rys. 1. Węzeł hybrydowy (na podst. [3])

Fig. 1. Hybrid node (on the basis of [3])

\section{Badania eksperymentalne}

Badania eksperymentalne prowadzono według zasad teorii planowania eksperymentu, realizując je na podstawie tzw. podejścia cybernetycznego. Węzeł hybrydowy, w analizowanym przypadku jego złącze doczołowe, rozpatrywano jako tzw. czarną skrzynkę, na wejściu której wprowadzono celowo wyselekcjonowane wcześniej parametry, decydujące o powstawaniu odkształceń, tzw. zmienne niezależne. Za najbardziej wpływające na skurcz poprzeczny uznano: energię liniową procesu spawania, odstęp progowy oraz grubość łącznika. Na wyjściu czarnej skrzynki rejestrowano odpowiedź od wprowadzonych parametrów wejściowych, tj. skurcz poprzeczny, stanowiący tzw. zmienną zależną. Opisaną czarna skrzynkę eksperymentu planowanego, wraz z jej najważniejszymi składowymi, pokazano na rysunku 2.
W przypadku wyboru trzech zmiennych niezależnych, wartości których mogą być zmieniane na dwóch poziomach (tj.: minimalnym oraz maksymalnym) - tablica I, eksperyment przeprowadzano na podstawie planu frakcyjnego dwuwartościowego, [7,8]. Liczba eksperymentów w jednym (wymaganym) bloku wynosi 8. Wartości minimalne i maksymalne zmiennych niezależnych odpowiadają rozpiętością wyselekcjonowanym parametrom technologiczno-konstrukcyjnym (tj. zmiennym niezależnym). W zależności od posiadanej objętości danych blok tych 8 eksperymentów może być realizowany wielokrotnie.

Eksperymenty prowadzono w warunkach zbliżonych do warunków produkcyjnych (na stanowisku, którego podstawę stanowił segment wielkogabarytowego łoża montażowego o wymiarach 4500x2000x480mm), z wykorzystaniem metod (tj. metody $136 \mathrm{w}$ osłonie $\mathrm{CO}_{2}$ ) oraz urządzeń spawalniczych powszechnie stosowanych w przemyśle okrętowym (tj. źródło prądu BLACK CAT 400 ST oraz zespół podający ZP S-1). Spoiny wykonywał spawacz z kilkunastoletnim doświadczeniem zawodowym w branży stoczniowej. Materiał podstawowy złącza doczołowego stanowiły fragmenty arkuszy blach stalowych gatunku AH36, natomiast jako materiał dodatkowy zastosowano drut proszkowy K-71TLF firmy Kiswel, o średnicy $\emptyset ~ 1,2 ~ m m$.

Jako elementy zamocowania próbek, symulujące założone postacie warunków brzegowych, zastosowano: sztywne zamocowanie na płycie konwencjonalnej (rys. 4) oraz podparcie przegubowo-nieprzesuwne na panelu l-core (rys. 4). Sytuacja ta jest zgodna z powszechnie obowiązującymi zasadami technologii wytwarzania wielkogabarytowych konstrukcji stalowych (np. okrętowych) i może symbolizować przypadek łączenia paneli sandwich (wraz z łącznikiem)

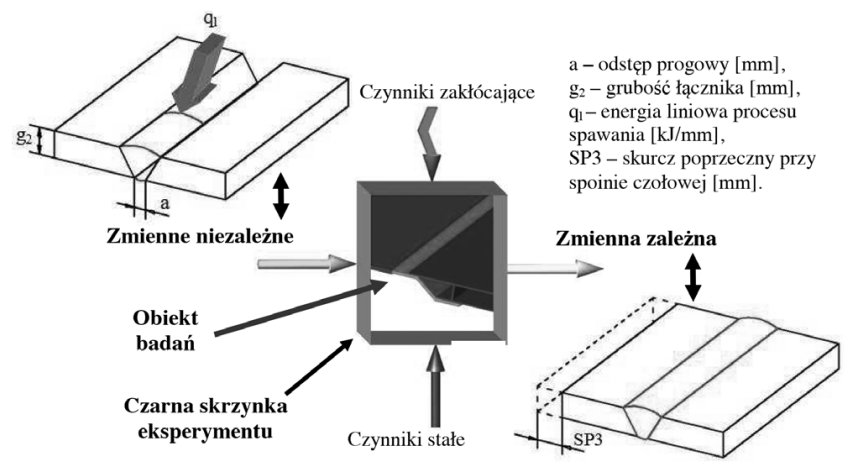

Rys. 2. Czarna skrzynka eksperymentu planowanego (na podst.[3]) Fig. 2. Planned experiment black box (on the basis of [3])

Tablica I. Plan eksperymentu - wartości unormowane (na podst. [3])

Table I. Plan of the experiment - normalised values (on the basis of [3])

\begin{tabular}{|c|c|c|c|}
\hline Nr eksperymentu & Energia liniowa $x_{1}\left(q_{1}\right)$ & Grubość łącznika $x_{2}\left(g_{2}\right)$ & Odstęp progowy $x_{3}(a)$ \\
\hline 1 & -1 & -1 & -1 \\
\hline 2 & +1 & -1 & -1 \\
\hline 3 & -1 & +1 & -1 \\
\hline 4 & +1 & +1 & -1 \\
\hline 5 & -1 & -1 & +1 \\
\hline 6 & +1 & -1 & +1 \\
\hline 7 & -1 & -1 & +1 \\
\hline 8 & +1 & +1 & +1 \\
\hline
\end{tabular}


z bardzo elementami konstrukcji konwencjonalnej o dużej sztywności, np. montaż sekcji kadłuba statku na pochylni, [3].

Metodę wyznaczania skurczu poprzecznego przedstawiono na rysunku 3 oraz w tablicy II. Natomiast kolejność operacji technologicznych, realizowanych podczas wykonywania złącza doczołowego na stanowisku badawczym zobrazowano na rysunku 4.

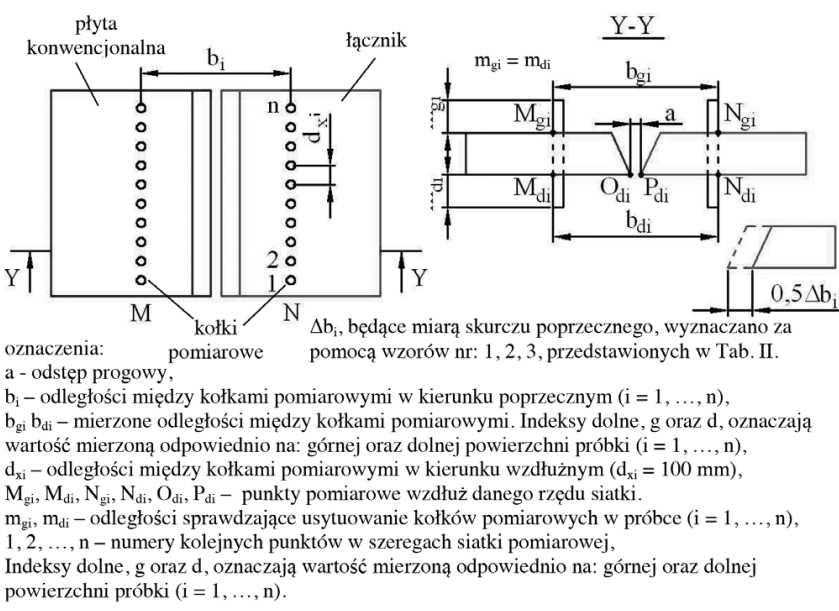

Rys. 3. Metoda wyznaczania skurczu poprzecznego (na podst. [3]) Fig. 3. Determinate of transverse shrinkage method (on the basis of [3])
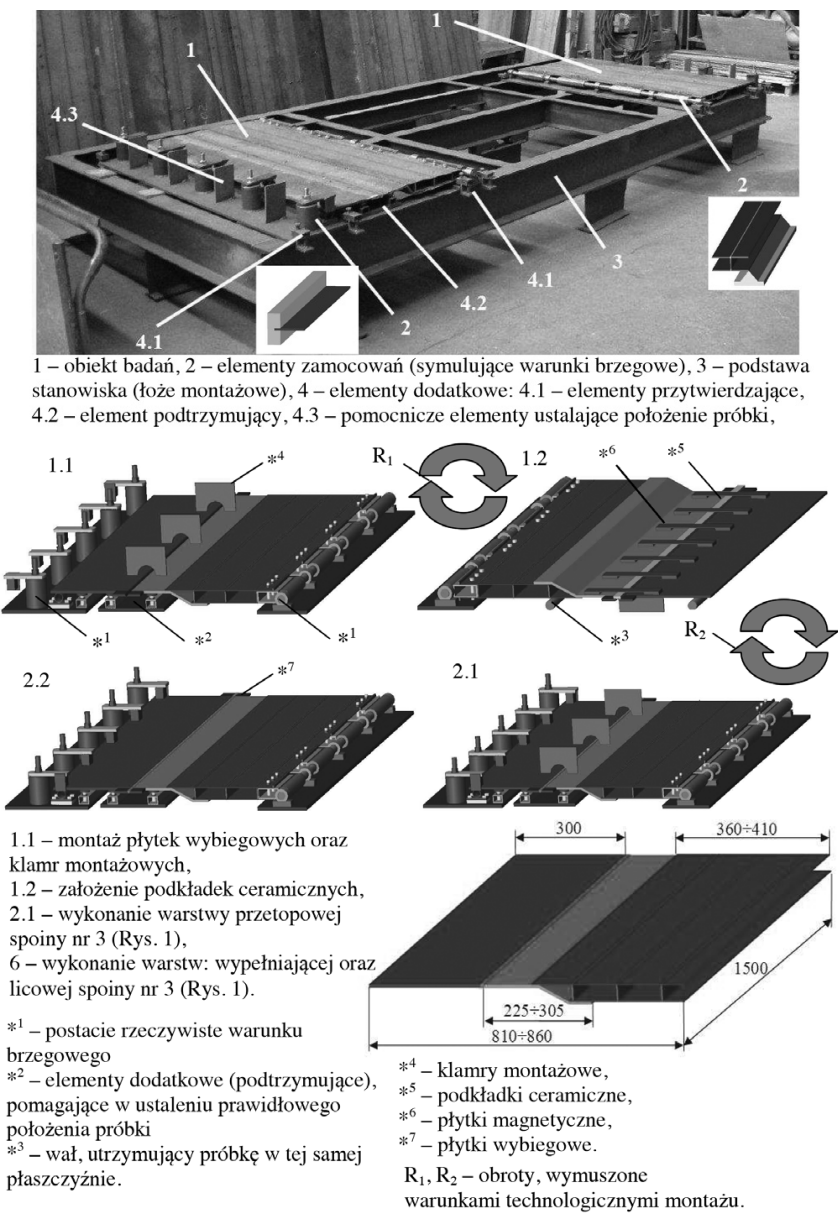

Rys. 4. Stanowisko badawcze oraz operacje technologiczne związane z wykonywaniem spoiny czołowej (na podst. [3])

Fig. 4. Research stand and technology operations in the making of butt weld (on the basis of [3])

\section{Wyniki badań}

Zależności między zmiennymi eksperymentalnymi mają charakter korelacyjny dlatego metodę wykorzystaną do prognozowania skurczu poprzecznego węzła hybrydowe-
Tablica II. Zależności matematyczne wykorzystywane przy wyznaczaniu skurczu poprzecznego (na podst. [3])

Table II. Mathematical dependence used for determinate of transverse shrinkage (on the basis of [3])

\begin{tabular}{|c|c|c|c|}
\hline Lp. & Opis & \multicolumn{2}{|l|}{ Wzór } \\
\hline 1 & $\begin{array}{c}\text { Średnia (arytmetyczna) róż- } \\
\text { nicy odległości między punk- } \\
\text { tami pomiarowymi, mierzona } \\
\text { w kierunku poprzecznym } \\
\text { (szerokość) }\end{array}$ & $b=\frac{1}{n} \cdot \sum_{i=1}^{n} \Delta b_{i}$ & (1) \\
\hline 2 & $\begin{array}{l}\text { Różnica odległości między } \\
\text { punktami pomiarowymi, } \\
\text { w kierunku poprzecznym }\end{array}$ & $\Delta b_{i}=b_{s i}-b_{p i}$ & (2) \\
\hline 3 & 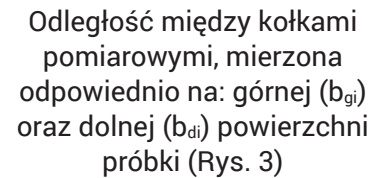 & $b_{s i}=b_{p i}=\frac{b_{g i}+b_{d i}}{2}$ & (3) \\
\hline \multicolumn{4}{|c|}{$\begin{array}{l}\text { oznaczenia: } b_{i}-\text { odległości między punktami pomiarowym } \\
\text { w kierunku poprzecznm }(i=1, \ldots, n), n \text { - liczba punktów pomiaro } \\
\text { wych w szeregu siatki pomiarowej, indeksy dolne: } p \text { - wartośc } \\
\text { mierzona przed spawaniem; } s \text { - wartość mierzona po spawanic }\end{array}$} \\
\hline
\end{tabular}

go oparto na analizie modeli regresji zmiennych zależnych względem zmiennych niezależnych.

Przy opracowywaniu wyników badań kierowano się zasadami zawartymi $\mathrm{m}$. in. w: $[7 \div 12]$, przy wykorzystaniu pakietu wspomagającego analizę statystyczną STATISTICA.

Jako aproksymowaną funkcję obiektu badań przyjęto wielomian ze składnikami liniowymi oraz interakcjami pierwszego rzędu, o postaci przedstawionej zależnością (4).

$$
y_{i}=b_{0}+b_{1} x_{1}+b_{2} x_{2}+b_{3} x_{3}+b_{12} x_{1} x_{2}+b_{13} x_{1} x_{3}+b_{23} x_{2} x_{3}
$$

gdzie:

yi - wyznaczana zmienna zależna (skurcz poprzeczny złącza doczołowego),

$\mathrm{b}_{0}, \mathrm{~b}_{1}, \mathrm{~b}_{2}, \mathrm{~b}_{3^{3}}, \mathrm{~b}_{12}, \mathrm{~b}_{13}, \mathrm{~b}_{23}$ - współczynniki regresji,

$x_{1}, x_{2}, x_{3}-z m i e n n e$ niezależne wybrane do eksperymentu (patrz rys. 2 oraz tab. I).

W kolejnym kroku wyznaczono poszczególne współczynniki regresji występującew równaniu (4), przy poziomie istotności $a=0,05$ (tzn. współczynniku ufności 95\%.).

Aby otrzymać zależności zawierających istotne współczynniki stosowano metody regresjikrokowo postępującej lub krokowo wstecznej. W ostateczności wybrano wyniki uzyskaneprzy pomocy pierwszej z metod, jako dającej wyższe wartości (tzn. bliższe jedności),najważniejszych z punktu widzenia oceny regresji, współczynników, tj.: współczynnika korelacji wielokrotnej (R), kwadratu współczynnika korelacji wielokrotnej $\left(R^{2}\right)$ oraz 2 skorygowanego kwadratu współczynnika korelacji wielokrotnej (Skoryg $\mathrm{R}^{2}$ ).

Wielomian opisujący zależność skurczu poprzecznego od przyjętych parametrów technologiczno-konstrukcyjnych przyjmuje postać równania (5). Wartości: skorygowanegokwadratu współczynnika korelacji wielokrotnej oraz statystyki F-Snedecora, dla badanej postaci odkształcenia pokazano w tablicy III, natomiast podsumowanie regresji wraz z wykazem istotnych zmiennych, dla analizowanej formy deformacyjnej, pokazano w tablicy IV.

$$
y_{S P 3}=b_{0}+b_{3} a-b_{12} q_{1} g_{2}+b_{13} q_{1} a
$$

gdzie:

ysP3 - skurcz poprzeczny złącza doczołowego, 
$b_{0}, b_{3}, b_{12}, b_{13},-$ współczynniki regresji,

$q_{1}, g_{2}$ a - zmienne niezależne wybrane do eksperymentu (patrz rys. 2 oraz tab. I).

$\mathrm{Na}$ podstawie przeprowadzonych obliczeń do modelu regresji wybrano trzy funkcje. Z tablicy III wynika, że obliczona wartość statystyki $F=18,50$ przekracza wartość krytyczną $F_{0,05,3,4}=6,59$ przy trzech stopniach swobody licznika i czterech mianownika (wartość krytyczna z tablic statystycznych [11]), ponadto wartość p jest mniejsza od poziomu istotności a. Oznacza to, że zależność (5) jest istotna statystycznie i może być wykorzystywana do prognozowania wartości zmiennej SP3 w funkcji zmiennych: $q_{1}, g_{2}$ a. Uzyskana wartość skorygowanego kwadratu współczynnika korelacji wielokrotnej (tab. III oraz tab. IV) świadczy o dopasowaniu powierzchni regresji do danych doświadczalnych na poziomie ponad $88 \%$.

Potwierdza to wykres normalności reszt dla analizowanego modelu (patrz rys. 5a). Usytuowanie punktów na tym wykresie pozwala stwierdzić, że rozkład reszt w przyjętym modelu nie odbiega znacząco od rozkładu normalnego. Jednoznacznie potwierdza to wysokie dopasowanie oszacowanego modelu liniowego do danych empirycznych.

Ocena wartości uzyskanych dla analizowanego skurczu poprzecznego złącza doczołowego węzła hybrydowego pozwala stwierdzić, że istotny jest odstęp progowy, a ponadto następujące współzależności pomiędzy przyjętymi zmiennymi niezależnymi: energia liniowaprocesu spawania x grubość płyty łącznika $\left(q_{1} \times g_{2}\right)$ oraz energia liniowa $x$ odstęp progowy $\left(q_{1} \times a\right)$.

Trafność prognozy oceniono poprzez porównanie wartości obliczonych na podstawie równania aproksymacyjnego z wartościami wyznaczonymi eksperymentalnie, co zobrazowano na rysunku 5b. Oba rodzaje w/w wartości umieszczono na jednym wykresie. Ponieważ wartości zmiennych niezależnych, uzyskanych obiema metodami, ułożyły się w pobliżu linii prostej, poprowadzonej z początku układu współrzędnych pod kątem $45^{\circ}$, można stwierdzić dobrą zgodność prognozy z rzeczywistością (największa różnica w wynikach dla obu metod wynosi 0,19 mm, natomiast najmniejsza 0,01 mm).

Warunkiem, jaki musi zostać spełniony podczas prognoz tworzonych na podstawie uzyskanego wielomianu aproksymacyjnego jest przynależność wykorzystywanych parametrów technologiczno-konstrukcyjnych do przestrzeni definicyjnej realizowanego planu eksperymentu.

Jednak nie w każdym przypadku można oczekiwać wyniku o porównywalnej jakości, ponieważ wartości parametrów technologicznych mają charakter probabilistyczny, co może prowadzić do większych różnic między prognozą a rzeczywistością.

a)

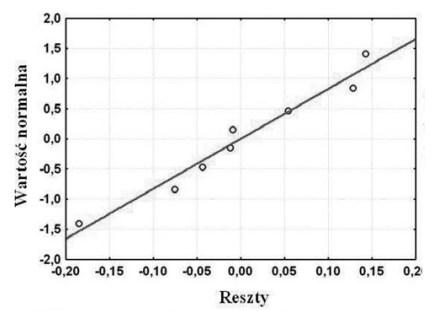

b)

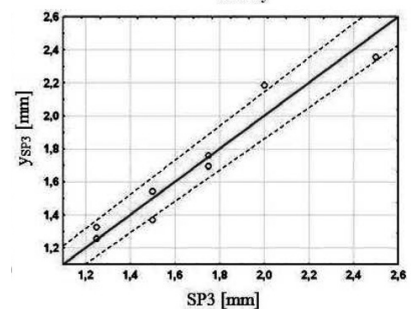

SP3 - wartości wyznaczone eksperymentalnie,

YSP3 - wartości aproksymowane

Rys. 5. Ocena trafności wartości prognozowanych: A - wykres normalności reszt dla przyjętego modelu, B - wykres dla skurczu poprzecznego złącza doczołowego (na podst. [3])

Fig. 5. Estimation of accuracy of predicted deformations: A - diagram of normality of residuals for received model, B - diagram for transverse shrinkage of butt joint (on the basis of [3])

Posługując się równaniem aproksymacyjnym, można ponadto pokazać, który z uznanych za istotne parametrów ma decydujący wpływ na otrzymaną postać deformacyjną. Współzależności pomiędzy parametrami technologicznymi dają się wyraźnie przedstawić wformie graficznej. Przy czym na wykresach trójwymiarowych mogą być pokazane równocześnie tylko dwa parametry. Wykresy tego typu pokazano na rysunku 6, z którego wynika, że odstęp progowy oraz energia liniowa mają znacznie większy wpływ na wartość skurczu poprzecznego, niż grubość łącznika. Zwiększenie odstępu progowego podnosi wartość skurczu. Zastosowane w eksperymencie wielkości tego parametru odpowiadają sytuacji rzeczywistej. Uzyskane wartości odkształceń (ich największe wartości), rzędu 2-2,5 mm, przy zastosowanych grubościach blach mogą być powodem niezadowalającej przydatności montażowej prefabrykowanych węzłów hybrydowych.

Tablica III. Porównanie wartości: skorygowanego kwadratu współczynnika korelacji wielokrotnej oraz statystyki F-Snedecora, dla SP3 (na podst. [3])

Table III. Comparison values: corrected square of coefficient of multiple correlation and F-Snedecor statistic, for SP3 (on the basis of [3])

\begin{tabular}{|c|c|c|c|}
\hline Symbol zmiennej zależnej & Wartość Skoryg. $R^{2}$ & $\begin{array}{c}\text { Wartość statystyki } F, \\
\text { wyznaczona na podst. } \\
\text { analizy regresji }\end{array}$ & $\begin{array}{c}\text { Wartość krytyczna } F_{k r,} \\
\text { tablic statystycznych (dla } \\
\text { poziomu istotności } a=0,05)\end{array}$ \\
\hline $\mathrm{y}_{\mathrm{SP} 3}$ & 0,88237 & $\mathrm{~F}(3,4)=18,502 ; \mathrm{p}<0,00828$ & $\mathrm{~F}(3,4)=6,59$ \\
\hline
\end{tabular}

Tablica IV. Zestawienie istotnych zmiennych, przy wykonywaniu metody regresji krokowo postępującej, dla SP3 (na podst. [3]) Table IV. Composition of significant variables for performed of progressive regress selection method, for SP3 (on the basis of [3])

Podsumowanie regresji zmiennej zależnej: $\mathrm{y}_{\mathrm{SP} 3}$

$\mathrm{R}=, 96580598 \mathrm{R} 2=, 93278119$ Skoryg. $\mathrm{R}^{\wedge} 2=, 88236709$

$F(3,4)=18,502 p<, 00828$ Błąd std. estymacji: , 14311

\begin{tabular}{|c|c|c|c|c|c|c|}
\hline $\mathrm{N}=8$ & Beta & Bł. Stand. Beta & B & Bł. Stand. B & $t(4)$ & Poziom $p$ \\
\hline W. wolny & & & 0,9888581 & 0,229485 & 4,30782 & 0,012568 \\
\hline $\mathrm{q}_{1}{ }^{*} \mathrm{a}$ & 0,937772 & 0,269964 & 0,016969 & 0,016969 & 3,47369 & 0,025498 \\
\hline $\mathrm{q}_{1}{ }^{*} \mathrm{~g}_{2}$ & $-0,319013$ & 0,219967 & $-0,011424$ & 0,011424 & $-1,45028$ & 0,220591 \\
\hline $\mathrm{a}$ & 0,256976 & 0,203224 & 0,039660 & 0,039660 & 1,26450 & 0,274711 \\
\hline
\end{tabular}


a)

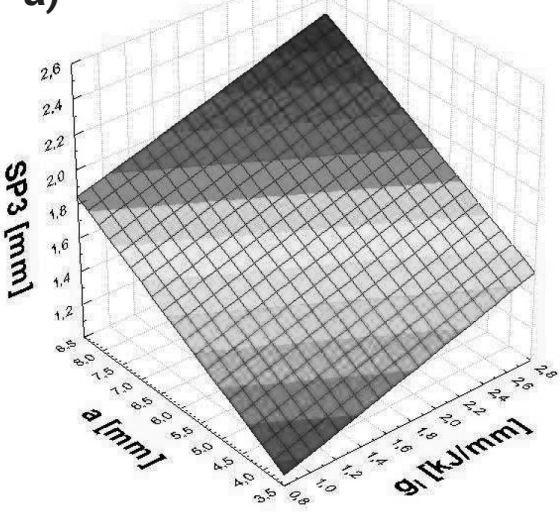

b)

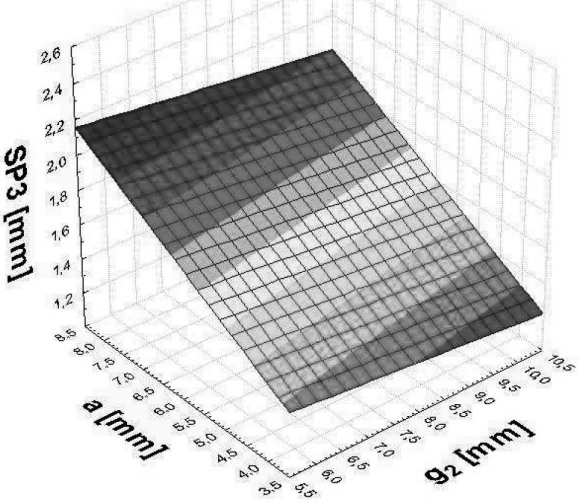

c)

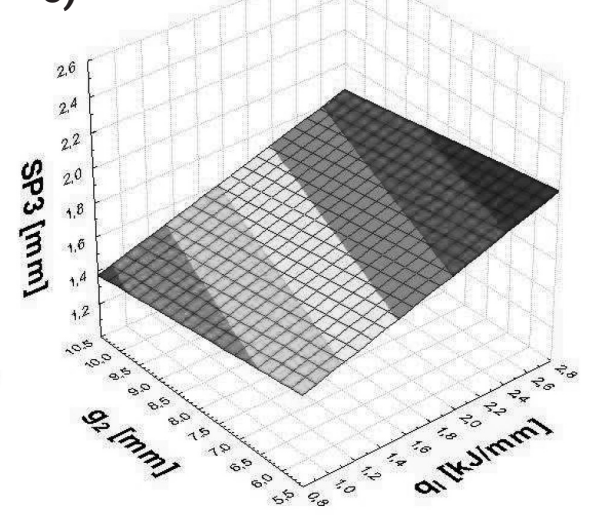

SP3 - skurcz poprzeczny przy spoinie czołowej [mm], a - odstęp progowy [mm], g - grubość łącznika [mm], q - energia liniowa procesu spawania [kJ/mm]

Rys. 6. Wpływ parametrów technologiczno-konstrukcyjnych na wartości skurczu poprzecznego, tzn.: A - odstępu progowego oraz energii liniowej, B - odstępu progowego oraz grubości łącznika, C - energii liniowej oraz grubości łącznika (na podst. [3])

Fig. 6. The influence of technological-constructional parameters on transverse shrinkage values, i.e.: A - welding gap and heat input, $\mathrm{B}$ - welding gap and thickness of the connecting element, $\mathrm{C}$ - heat input and thickness of the connecting element (on the basis of [3])

\section{Wnioski}

Ocena wyników eksperymentu planowanego pozwala na określenie parametrów technologiczno-konstrukcyjnych o istotnym znaczeniu dla wartości analizowanej postaci odkształcenia. Pozwala również na opracowanie modelu matematycznego w celu prognozowania skurczu poprzecznego w złączu doczołowym węzła hybrydowego. Model ten umożliwia tym samym poszukiwanie rozwiązań technologicznych gwarantujących utrzymanie geometrii konstrukcji węzła w założonych tolerancjach wymiarowych, co wpłynie na poprawę jego przydatności montażowej. Wartykule udowodniono dobrą trafność prognozy. Ponadto wykazano, że istotny wpływa na wartość skurczu poprzecznego mają wszystkie wyselekcjonowane do eksperymentu zmienne niezależne, tj.: odstęp progowy, energia liniowa oraz grubość łącznika. Należy jednak pamiętać, że koniecznym warunkiem, jaki musi zostać spełniony, aby zapewnić rzetelność prognozy jest przynależność parametrów technologiczno-konstrukcyjnych do przestrzeni definicyjnej realizowanego planu eksperymentu.

\section{Literatura}

[1] Urbański T.: Węzeł hybrydowy - prognozowanie odkształceń spawalniczych panelu Icore na podstawie planowanego eksperymentu dwuwartościowego, Przegląd Spawalnictwa Nr 3/2012, str. 16-22.

[2] Urbański T.: Węzeł hybrydowy - technologiczność wielkogabarytowych konstrukcji spawanych - wprowadzenie, Przegląd Spawalnictwa $\mathrm{Nr} 11 / 2010$, str. 21-25

[3] Urbański T.: Metoda prognozowania odkształceń spawalniczych węzła hybrydowego na podstawie badań eksperymentalnych, Rozprawa doktorska, Zakład Konstrukcji, Mechaniki i Technologii Okrętów, Wydział Techniki Morskiej, Zachodniopomorski Uniwersytet Technologiczny w Szczecinie, Szczecin 2009.

[4] Shipbuilding and Repair Quality Standard IACS, London 1996: Part A. Shipbuilding and Repair Quality Standard for New Construction; Part B. Repair Quality Standard for Existing Ships.

[5] Norma zakładowa: T100-1, 2001. Stalowy kadłub statku. Dokładność konstrukcji kadłuba, Stocznia Szczecińska S.A.
[6] Metschkow B., 2001. Wpływ spawania na jakość konstrukcji prefabrykowanych, Laboratoria Technologiczne - Aspekty Utrzymania Wysokiej Jakości Wyrobu, XI Międzynarodowa Konferencja, Zintegrowane Systemy Zarządzania w Przemyśle.

[7] Montgomery D.C.: Design and analysis of experiments. John Wiley \& Sons, Inc. fifth edition, New York, 2001.

[8] Polański Z.: Planowanie doświadczeń w technice, PWN, Warszawa 1984.

[9] Dobosz M.: Wspomagana komputerowo statystyczna analiza wyników badań, Akademicka Oficyna Wydawnicza EXIT, Warszawa 2004.

[10] Kołodziński E.: Symulacyjne metody badania systemów, PWN, Warszawa 2002.

[11] Oktaba W.: Elementy statystyki matematycznej i metodyka doświadczalnictwa, PWN, Warszawa 1974.

[12] Nikiel G.: Opracowanie statystyczne wyników badań doświadczalnych z wykorzystaniem programu ReGreg (http://www.ath.bielsko.pl). 